\title{
Systematic Review \\ Computational Thinking and Educational Technology: A Scoping Review of the Literature
}

\author{
Jesús Acevedo-Borrega *D, Jesús Valverde-Berrocoso ${ }^{(D)}$ and María del Carmen Garrido-Arroyo
}

check for updates

Citation: Acevedo-Borrega, J.; Valverde-Berrocoso, J.; Garrido-Arroyo, M.d.C. Computational Thinking and Educational Technology: A Scoping Review of the Literature. Educ. Sci. 2022, 12, 39. https://doi.org/ $10.3390 /$ educsci12010039 Academic Editor: João Piedade Received: 9 November 2021 Accepted: 31 December 2021 Published: 8 January 2022

Publisher's Note: MDPI stays neutral with regard to jurisdictional claims in published maps and institutional affiliations.

Copyright: (C) 2022 by the authors. Licensee MDPI, Basel, Switzerland. This article is an open access article distributed under the terms and conditions of the Creative Commons Attribution (CC BY) license (https:// creativecommons.org/licenses/by/ $4.0 /)$.

\author{
Department of Education Sciences, Faculty of Teacher Education, University of Extremadura, Avenida de la \\ Universidad s/n, 10003 Cáceres, Spain; jevabe@unex.es (J.V.-B.); cargarri@unex.es (M.d.C.G.-A.) \\ * Correspondence: jeacbo@unex.es
}

\begin{abstract}
Interest in computational thinking (CT) in the scientific community has increased significantly in the last 4 years, as evidenced by the numerous systematic reviews carried out. However, there is a lack of reviews that update the emerging conceptualization of CT and which also examine the roles of the school curriculum and teachers in the face of CT. A systematic literature review (SLR) consists of a collection of research conducted according to previous criteria with the aim of answering research questions with validity and quality. For this reason, the PRISMA-ScR statement was followed. Articles published in scientific journals, from Scopus and WoS, between January 2018 and August 2021 were included, in the English or Spanish language. The initial search resulted in 492 articles, to which the inclusion-exclusion criteria were applied. The final sample of texts for the present systematic review was $n=145$. The texts were analyzed from three perspectives: conceptual, documentary and pedagogical. Thus, a renewal of previous literature reviews was carried out, updating the situation with research from recent years and new data, obtained to contribute to the collective intelligence on methodological strategies ( $80 \%$ of the sample was divided into "plugged" and "unplugged"); educational (more than 50\% studied CT evaluation); and resources, including a collection of more than 119 educational resources.
\end{abstract}

Keywords: computational thinking; problem solving; 21st-century skills; education; systematic literature review

\section{Introduction}

Computational thinking (CT) is a transversal and complex competence that goes beyond the use of computers and writing code. It is considered an ideal medium for the development of 21st-century skills [1]. Its purpose is not exclusively to promote students to opt for training in computing careers. It is about promoting the integral development of citizenship within a free and democratic society [2]. The myth of the "digital native" has been quite detrimental when considering the need for a "digital education" for all those born in the midst of the technological revolution. The effects of the pandemic have shown how the "digital divide" continues to be a very relevant educational problem.

Although the definition of CT has multiple approaches and perspectives [3], its basic component is the creation of "logical artifacts" that make ideas explicit and concrete so that they can be interpreted and applied in computational artifacts. CT focuses on "abstraction", which is a tool of the constructive mind, and its "computational representation" [4]. Scientific knowledge about CT has a multidisciplinary character, including computer science, cognitive science, and educational science.

Interest in CT within the scientific community has increased significantly, as evidenced by the numerous systematic reviews carried out in the last 4 years. Fagerlund et al. [5] proposed a review of scientific articles relating to experiences of inclusion among practices with Scratch in primary education (2007-2019). The selected articles $(n=30)$ were analyzed with Dr. Scratch, a software created to analyze projects produced with Scratch, to determine 
which parts of the CT were more developed using the software created by Resnick. Palts and Pedaste [6] conducted a review with the aim of designing a new conceptual model based on the studies analyzed $(n=65)$. Their results proposed three clearly differentiated phases within a repetitive cycle. They also described a practical example for the optimal development of CT-related skills. Xia and Zhong [7,8] conducted reviews focused on the field of educational robotics and mathematics. Cabrera [9] carried out a review on the previous preconceptions of CT in primary education teachers. Along the same lines, is the review by Taslibeyaz et al. [10] (2011-2018) of a sample of university students, which included questions related to the perception of the CT concept. They related three dependent variables of CT (attitude and motivation, problem solving and programming skills) to the tools found in the review. Popat and Starkey [11], as a result of a systematic review (1988-2017), used a diamond representation to describe how CT influences the educational process. In their analysis of $\mathrm{CT}$, they included social skills, such as collaboration, and cognitive skills, such as self-control, and teaching methods, such as active learning. Zhang and Nouri [12] focused their review (2007-2018) on secondary education to identify, in a comprehensive way, the skills linked to CT developed with the support of Scratch. Kakavas and Ugolini [13] conducted a review on CT in primary education (2006-2018). They identified different studies depending on the CT activity developed (plugged, unplugged or a combination of both), as well as a selection of tools for CT assessment. The systematic review by Tang et al. [14] analyzed the context, tools and validity of the evidence provided for CT assessment. Hsu et al. [15] conducted a review from January 2006, with the publication of Wing [16], to 2017. Conceptual questions were raised, linking CT with programming languages. The analysis of the methodological strategies applied in the papers under review stands out. Tikva and Tambouris [17] developed a conceptual model based on a systematic literature review on CT through programming for compulsory education (K-12). Six areas of CT were identified: (1) knowledge base of CT (concepts, skills, practices, self-perception and attitudes); (2) assessment of CT, by direct (tests, observations, artifact analysis) or indirect (self-report) methods; (3) learning strategies for CT based on games, simulations, problem solving, projects, scaffolding and collaboration; (4) individual and contextual variables (demographic, psychological, cognitive and academic factors); (5) tools (programming software and learning communities; robotics and microcontrollers; CT-specific educational resources); and (6) competency development (curriculum for CT teaching, initial and ongoing teacher training). It is evident that some of the relationships between the identified areas have not been sufficiently studied. From among them, springs forth the knowledge about which tools best develop certain learning strategies. It can also be seen which learning strategies favor the acquisition of CT or which variables significantly affect its development. Meanwhile, the interest of researchers was especially focused on the area of assessment, where efforts have been made to develop validated strategies for general use in self-report mode. The studies do not accurately reflect the application of the tools and learning approaches used.

In conclusion, there is a lack of reviews that update the emerging conceptualization of $\mathrm{CT}$ and examine the role of the school curriculum and the role of teachers in the face of CT. Educational systems are renewing their contents to include these digital competencies $[18,19]$. Teachers face several challenges in integrating CT into their teaching practice: weak technological infrastructure and a lack of time for pedagogical design and creation of teaching materials, as well as insufficient training [20,21]. In addition, there is low-level knowledge about CT and its teaching methodology [22,23].

\section{Materials and Methods}

A systematic literature review (SLR) consists of the collection of research conducted according to previous criteria with the aim of answering research questions. To guarantee the validity and quality of the SLR, it must be carried out under objective criteria that provide the process with transparency, clarity and precision. Scoping reviews, a specific type of systematic review, are commonly used to clarify working definitions and conceptual 
boundaries of a topic or field [24]. For this reason, the PRISMA-ScR statement was followed in Supplementary Material (https://bit.ly/3G7S1tu (accessed on 29 December 2021)), which comprises a total of 20 elements to identify eligibility criteria, information sources, search strategy, selection process, data collection process and a data list. The usefulness of an SLR is not limited to the synthesis of research results but also provides the possibility of identifying categories and trends [25]. This review updates those conducted by Hsu et al. [15] and Kakavas and Ugolini [13] with data from the last five years to provide an update of the literature which is enriched with aspects not originally integrated, such as those related to teacher training and the educational curriculum.

First, as shown in Table 1, the research questions (RQ) were organized around three dimensions: (a) a conceptual framework to analyze the relationships between the key-words identified in the literature (RQ1); (b) documentary framework to identify themes, geographical location, Q levels of the journals and research methodologies used (RQ2-RQ6); and (c) pedagogical framework (RQ7-RQ9) to recognize educational levels, areas of knowledge, pedagogical approaches, teaching practices and didactic tools in the studies analyzed.

Table 1. Scope, questions and coding criteria.

\begin{tabular}{|c|c|c|}
\hline Scope & Investigation Questions & Initial Coding Criteria \\
\hline $\begin{array}{l}\text { Conceptual } \\
\text { Framework }\end{array}$ & RQ1. What is the conceptual relationship surrounding the term CT? & Word frequency, keywords, nodes and C.D. \\
\hline \multirow{5}{*}{$\begin{array}{l}\text { Documental } \\
\text { Framework }\end{array}$} & $\begin{array}{l}\text { RQ2. What is the distribution of items according to CT } \\
\text { dimensions and their position in the database? }\end{array}$ & Databases, dimensions, quartile and year \\
\hline & $\begin{array}{l}\text { RQ3. What and how are the interactions and relationships } \\
\text { between the authorships? }\end{array}$ & Co-authorship, co-citation and gender \\
\hline & RQ4. What are the topics from which the articles are published? & Disciplines and subject areas \\
\hline & $\begin{array}{l}\text { RQ5. What is the geographical distribution of publications and } \\
\text { their relationship with their inclusion or not in the } \\
\text { official curriculum? }\end{array}$ & Country and language \\
\hline & RQ6. What are the research methodologies and sample sizes? & Approaches, methodologies and sample \\
\hline \multirow{3}{*}{$\begin{array}{l}\text { Pedagogical } \\
\text { Framework }\end{array}$} & $\begin{array}{l}\text { RQ7. What are the educational levels and areas of } \\
\text { knowledge involved? }\end{array}$ & Types of practice, educational levels and subjects \\
\hline & $\begin{array}{l}\text { RQ8. What are the methodological characteristics for the } \\
\text { development of CT? }\end{array}$ & Types of resources and results \\
\hline & RQ9. What are the didactic tools used for the development of CT? & Resources \\
\hline
\end{tabular}

To locate a sample that provides answers to the questions posed, eligibility criteria and information sources were established. Articles published in scientific journals between January 2018 and August 2021 were included, which have, in their title, abstract or keywords, the concepts "Computational Thinking", "Experience", "Program", "Background", "Intervention" and "Experiential Learning", in the English or Spanish language. Theoretical and empirical studies with quantitative or qualitative methods were included. The exclusion criteria applied were for articles that did not develop an educational practice related to CT. Additionally, texts that were not articles were excluded. The databases used to search the texts were Web of Science (WoS) and Scopus. Keywords were used in each of the databases. The search syntaxes were included in the coding sheet in Supplementary Material (https: / / bit.ly /3G3n35O (accessed on 24 October 2021)).

Figure 1 shows how the initial search resulted in 492 articles, of which 145 were duplicates. Following the inclusion-exclusion criteria, all the researchers analyzed the 347 articles on the basis of the title and abstract. After reaching a consensus on the results, 188 texts were excluded. Nine of them were withdrawn because they were not accessible, leaving 150 that were analyzed in full text in a second selection process. Once again, the researchers independently carried out a second screening that resulted, by agreement, in the exclusion of 5 more articles. The final sample of texts for the present systematic review was $n=145$. 

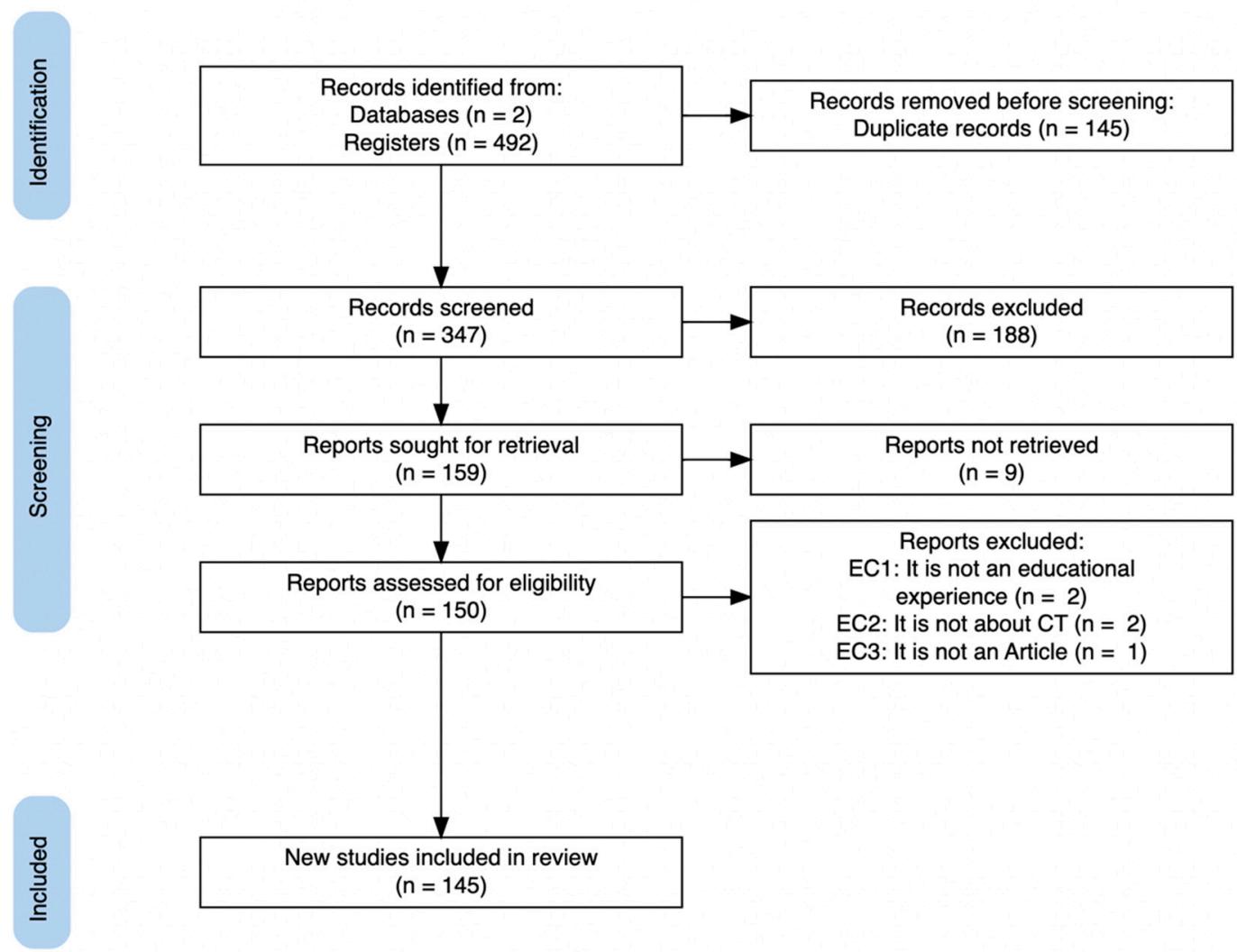

Figure 1. Flow chart of the literature selection process.

Several tools were used during the data coding and synthesis process. First, the Zotero bibliographic manager was used to collect the information. The synthesis of the information was also carried out using a coding sheet with 29 fields. Finally, VOSViewer, RAWGraphs, Litmaps and NVivo 12 Plus were used for the comparative and analytical scrutiny of the results. The authors of the review were involved in all the phases required by PRISMA.

\section{Results}

\subsection{What Is the Conceptual Relationship Surrounding the Term CT?}

Figure 2 shows seven clearly differentiated clusters, obtained from the co-occurrence of the keywords of the articles. The first cluster that stands out is the blue one, and, in it, the direct relationship of CT to "Methodologies" can be observed. In the red cluster, "Competence", the three dimensions of CT related to 21st-century skills, and the educational curriculum are perceivable. Between both clusters, a series of brown elements can be found that revolve around "Problem Solving".

This gives way to the green and orange clusters that offer up a relationship between elements that allow the development of the CT. While the green cluster is related to "Software", specifically to programming languages, the orange cluster is related to "Hardware", such as robotics. Flowing between both clusters, you can find the one formed by the yellow color, where you can see the "Disciplines" such as STEM. Finally, the purple cluster shows the elements related to the different "Educational Levels".

Figure 3, elaborated with NVivo 12, is a conceptual network of nodes and subnodes from the coding of the complete content of the items based on the three dimensions of the CT. This follows Brennan and Resnick [26] with regards to the dimensions in which CT can be studied and takes into account other studies [1,27-29]. 


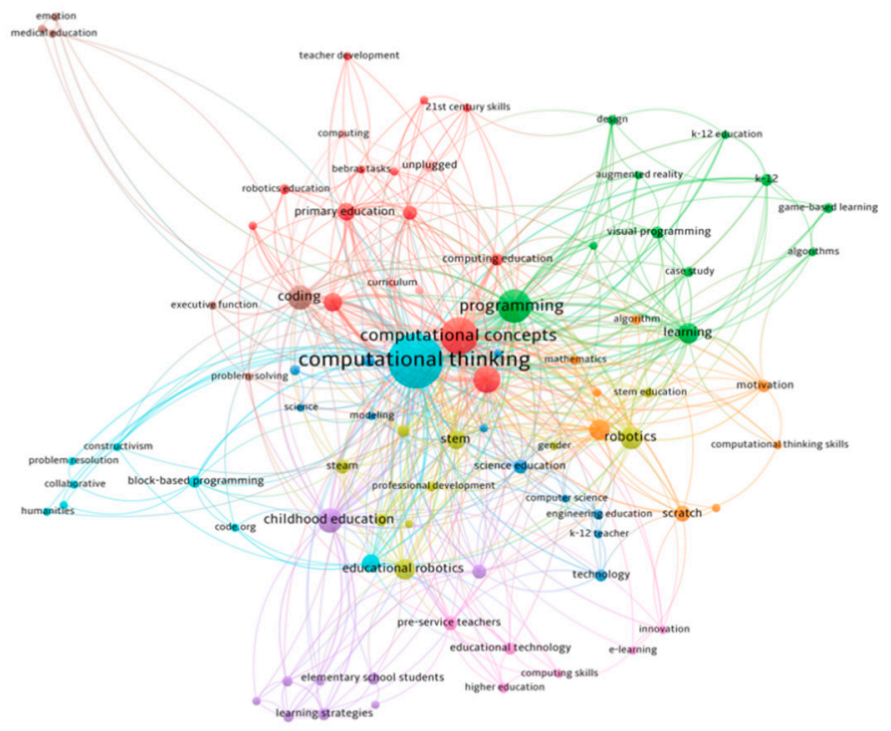

Figure 2. Co-occurrence map by keywords (minimum frequency 2).

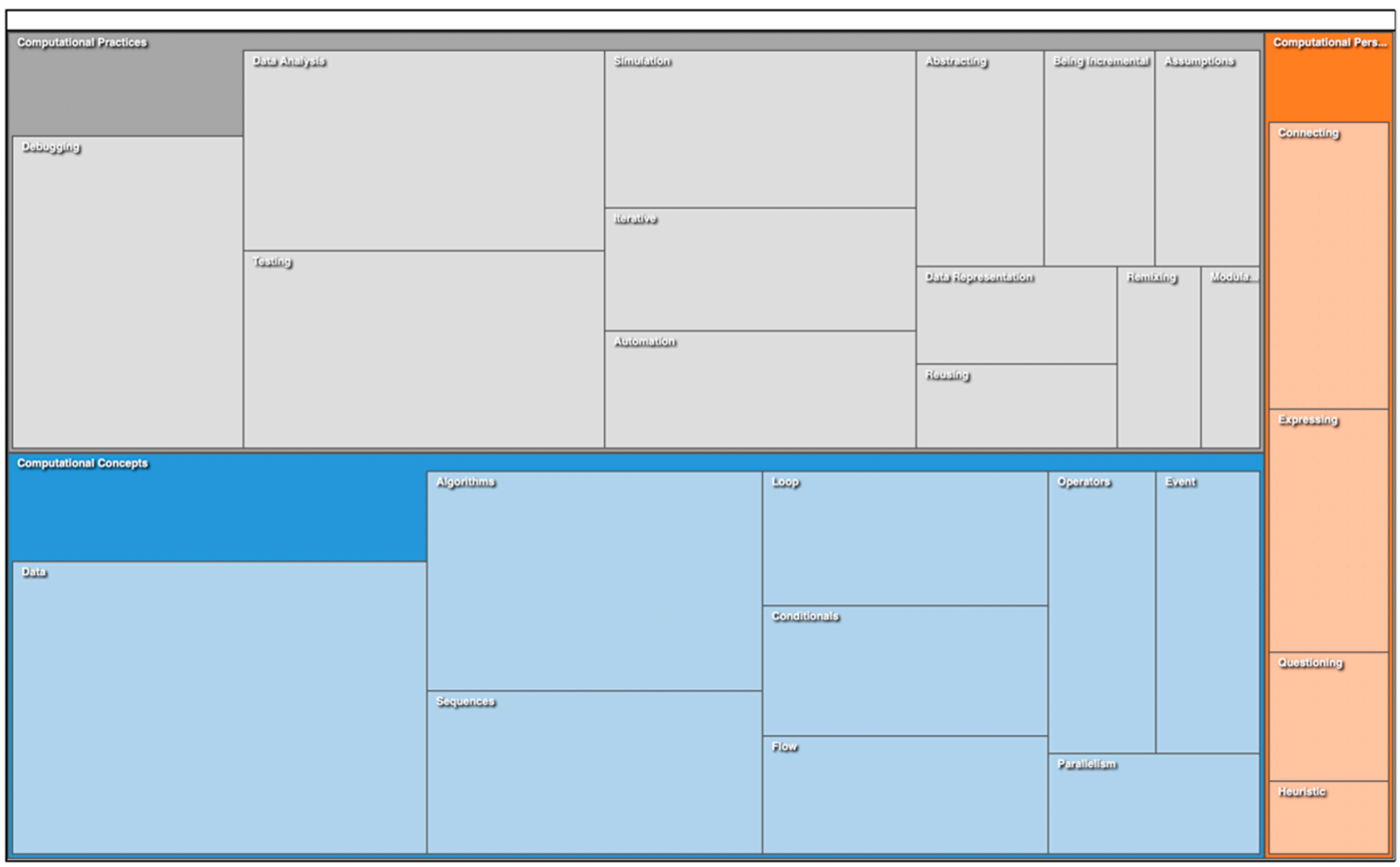

Figure 3. Conceptual network of nodes and subnodes based on the three dimensions of the CT.

Figure 3 shows how the "conceptual" (blue) and "practical" (grey) dimensions are equally represented, while the "perspective" (orange) dimension is relegated to second place. It should be noted that "data", "algorithms" and "sequences" are the most developed concepts, while "testing", "data analysis" and "debugging" are the most worked practices. In the case of the third dimension, "connection" and "expression" are the most frequent, while "heuristics" and "questioning" show a lower number of frequencies. A similar result was obtained with "reuse" and "modularization" being the least used practices and "parallelisms", "events" and "operations" being the most developed concepts.

3.2. What Is the Distribution of Items According to CT Dimensions and Their Position in the Database?

The first quartile (Q1) includes 65 articles (44.82\%). There are 42 (28.96\%) corresponding to the second quartile (Q2). In the third quartile (Q3) a total of 21 articles have been 
published, representing $14.48 \%$ of the total. Finally, nine articles $(6.2 \%)$ belong to the last quartile (Q4). The number of articles published in non-indexed journals in these quality indexes, is eight $(5.51 \%)$.

The three dimensions were subjected to an analysis, taking into account the databases and the level of quality of the journals in which the articles were published, and a new vision was obtained, as shown in Figure 4. Last place goes to "perspective". However, regardless of the dimension, it is evident that most of the articles had a high quality, being published mostly in Q1 and Q2.

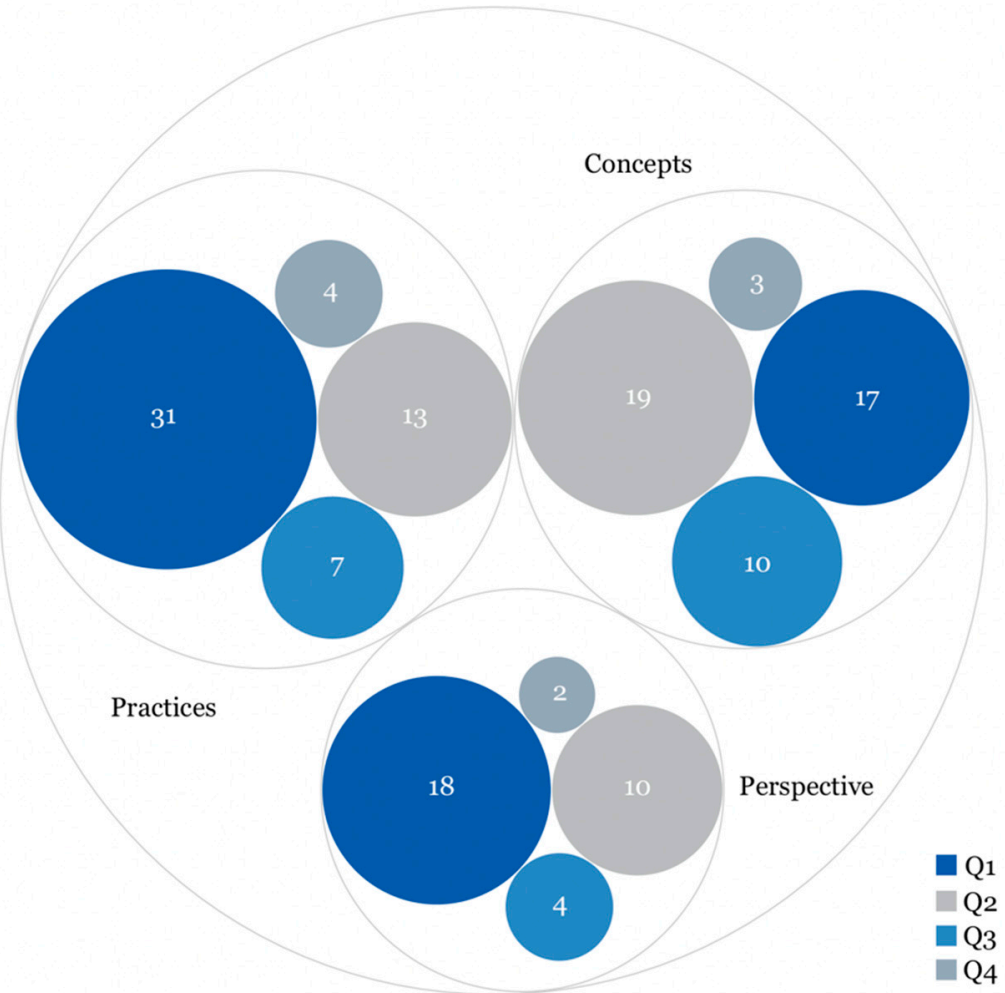

Figure 4. Distribution of items for each CT dimension and Q level. Prepared with RAWGraphs.

\subsection{What and How Are the Interactions and Relationships between the Authorships?}

Figure 5 shows the relationship between the articles (with DOI) that make up the review sample and their citations over time. The relationship is evidenced not only among themselves, but also with 10 other very relevant articles on CT [16,30-37]. As can be seen, the bulk of lines link directly to the authors mentioned. However, the lines linking them to each other are tiny in comparison.

\subsection{What Are the Topics about Which the Articles Are Published?}

Among the thematic areas, "Social Sciences" stands out with a large percentage at $77.28 \%$ of the publications with 112 articles. It is followed by "Computer Sciences" at 7.59\% and "Engineering" at $6.21 \%$, as a result of the 11 and 9 publications that were associated, respectively, with their areas.

Among the disciplines, four represent $83.49 \%$ of the publications: "Education" stands at $69 \%$, being the most productive with 100 articles. It is followed by "Communication", "Computer Science" and "Engineering" at $4.83 \%$ each. 


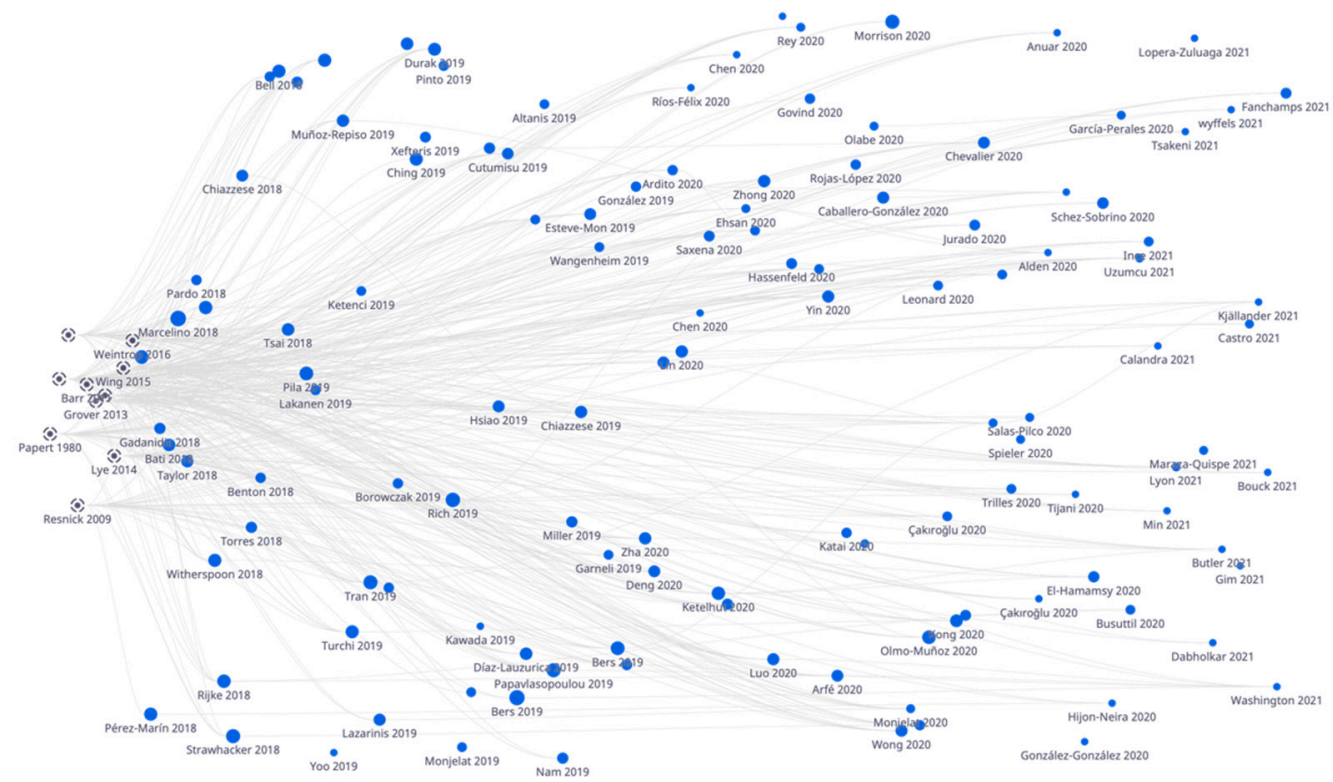

Figure 5. Co-authorship map of articles in possession of DOI. Elaborated with Litmaps.

3.5. What Is the Geographical Distribution of Publications and How Does This Relate to Their Inclusion or Not in the Official Curriculum?

The United States, Spain, Turkey, Korea and the United Kingdom make up $51.06 \%$ of the sample. Of this percentage, $21.39 \%$ corresponds to the United States, with 31 publications, and $14.49 \%$ to Spain, with 21 published articles. Turkey, Korea and the United Kingdom had a publication frequency of 9,7 and 6 respectively.

Thus, the United States and Spain are the nations that stand out with the greatest power. However, neither country includes CT in the official curriculum, leaving it up to the states or autonomous regions to decide how to incorporate it into educational practice. The countries that follow them in number of publications, Turkey, South Korea and the United Kingdom, do have CT integrated into their educational systems [38].

\subsection{What Are the Research Methodologies and Sample Sizes?}

The main research approach of the publications was a quantitative and mixed method, combining quantitative and qualitative approaches. Both are equal with $37.26 \%$ of the sample, which means a total of 54 articles for each mode. Third place is occupied by the qualitative methodology with 37 articles (25.53\%).

Based on the research methods applied in the studies, first place can be evidenced for instructional design with a total of 50 articles $(34.5 \%)$. This is followed by the quasiexperimental method with 34 publications $(23.46 \%)$. Case studies were included in 23 articles (15.87\%). The 13 experimental studies account for $8.97 \%$, followed by $5.52 \%$ corresponding to the design-based research (DBR) method. Adding both percentages to those obtained by exploratory data analysis (seven articles), they represent more than $90 \%$ of the sample.

\subsection{What Are the Educational Levels and Areas of Knowledge Involved?}

Educational practices were carried out equally in formal educational contexts. This includes those ranging from early childhood education to higher education and non-formal and those outside educational institutions. Specifically, $48 \%$ of the practices were carried out in both settings. Seventy articles were developed in a formal context and another seventy in a non-formal one. Only $4 \%$ of the 145 articles analyzed (five articles) mixed both contexts.

The formal educational levels in which research was carried out included early childhood education at $9.66 \%$, which is in fourth position (14 articles). Secondary education 
was the third most researched educational level with 20 publications (13.8\%). The educational levels most chosen by researchers were higher education and primary education, at 20.01 and $40.02 \%$, respectively. Higher education was found in 29 articles, while primary education was found in 58 of the 145 articles.

Outside the scope of formal educational institutions, $0.69 \%$ corresponded to family education: a single article that included fathers and mothers in the development of computational thinking. Finally, we found at identical percentages, $7.59 \%$, the practices addressed to active teachers and those applied at different levels.

Meanwhile, the subject of "Programming" was present in $63.48 \%$ of the publications analyzed and the rest of the subjects did not reach 10 publications. "Mathematics" was the primary subject found in nine publications (6.21\%), followed by "Computer Science" and "STEM" (4.83\%), with a total of seven articles, respectively. In six articles, CT was developed in an interdisciplinary way (4.14\%), in five articles within the subject "Science" $(3.45 \%)$ and in four articles it was worked from the subject "Engineering" $(2.76 \%)$. The subject "Art" was represented in three studies (2.07\%).

\subsection{What Are the Methodological Characteristics for CT Development?}

"Plugged" resources, those that need a digital environment to be used, and "unplugged", tangible materials that can be used analogically, accounted for $80 \%$ of the sample, with 57 articles, respectively. The rest opted for combining resources of both types, for example, through robotics.

Figure 6 shows the relationship between formal educational levels and the types of resources used in their research. It can be seen that, in early childhood education, a greater number of disconnected or unplugged, tangible resources were used, given that half of the articles (seven) opted for this type of educational material. In primary education, 33 publications strongly suggested a mixed use of resources, while, in secondary education, with 12 texts out of a total of 20, and higher education, with 14 pieces of research out of a total of 27 , we see the use of digital or connected resources.

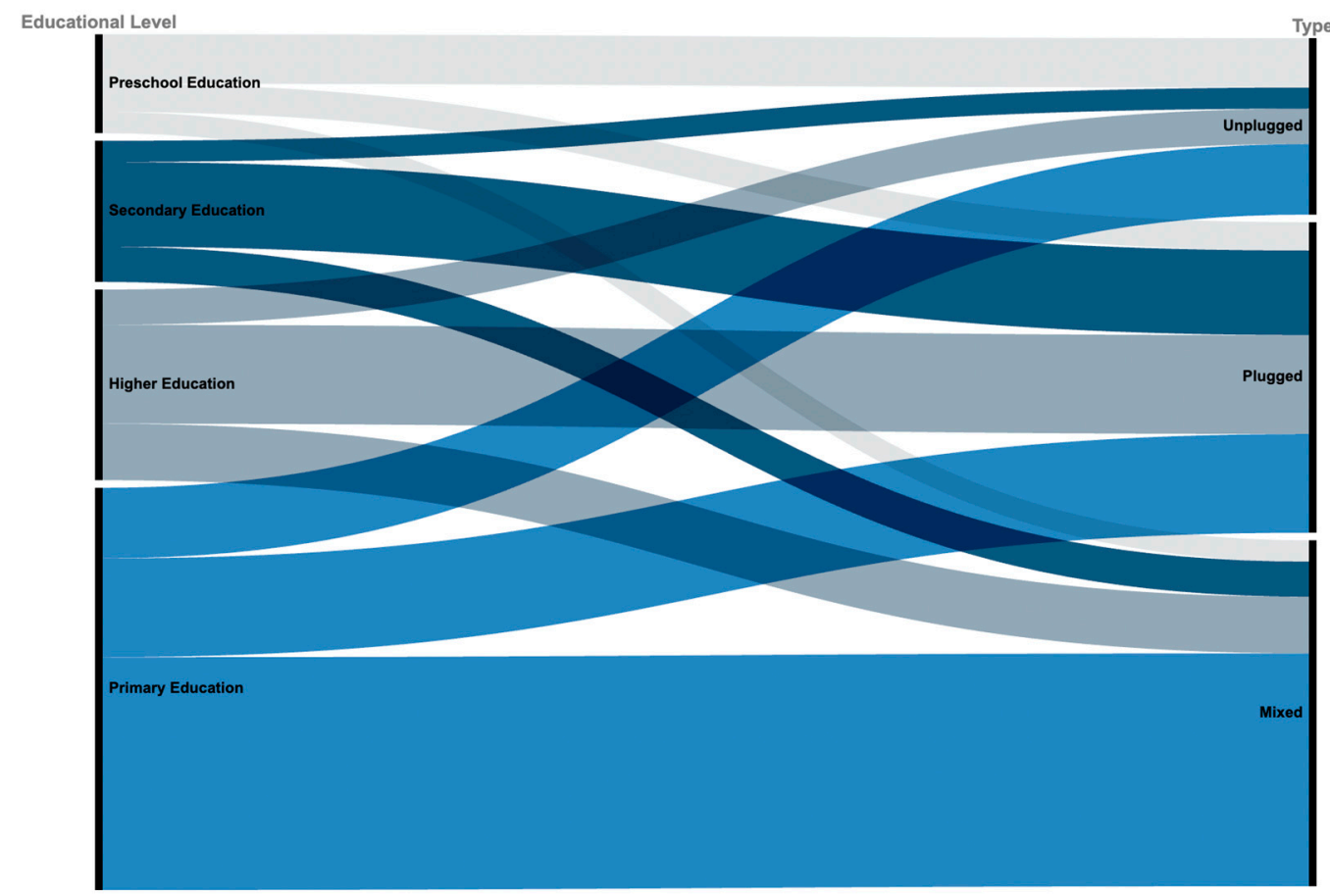

Figure 6. Educational levels related to type of resources. Developed with RAWGraphs.

In 81 articles, findings were made on different participant attitudes towards educational practices in CT. An increase in motivation [39], a good predisposition to different levels of difficulty [40,41], a preference between a digital and an analog interface [42], a 
positive attitude towards science [43] or an improvement in autonomy [44], among others, were demonstrated.

Seventy-nine items sought to assess the $\mathrm{CT}$ in one of its three dimensions. We witnessed the evaluation of "abstraction", "generalization", "judgment" and "decomposition" [45-47], the effectiveness of the use of unplugged resources [48], the evidence of a development of logical thinking [49] or the relationship of the concept with an innovative design [50], among others.

Coding was evaluated in 34 publications, which represents more than $70 \%$ of the articles, showing, as a result, that, for example, more programming activities with App Inventor improved student performance [51]. It is also concluded that, through visual programming and robotics, programming skills can be developed [52]. It is also observed that the progress obtained through coding lasts over time [53].

The integration of CT into the curriculum was studied in 27 articles. The results show how interdisciplinarity is an effective strategy through STEM [54] or the incorporation of coding and robotics in curricular content for the development of CT skills [55]. At the same time, the assessment of student learning outcomes was evaluated in 21 studies, with higher performance observed compared to transmissive teaching methods [56]. There was also evidence of improved cognitive and social skills compared to those who were not trained in CT [57].

In 10 investigations, the impact was evaluated according to the gender of the sample members, finding that one of the best ways to attract women to CT is through unplugged resources [58]. This overcomes stereotypes that "boys are better at programming than girls" [59]. Teaching practices were the subject of research in six articles. It was shown that the most effective CT teachers are those who know how to integrate didactic and methodological aspects and not those who are the best programmers [60].

With regard to mathematical competence, a total of five studies showed a positive effect on its development after the implementation of coding [61]. With respect to digital competence, one study found a relationship between the CT and the students' perception of an improvement in their digital skills [62].

\subsection{What Are the Didactic Tools Used for the Development of the CT?}

Figure 7 provides an overview of the specific resources used by the authors based on the types of resource, namely: "hardware", "software" and "tools". Physical resources account for $34.45 \%$ of the sample, digital resources account for 37.81 and $27.73 \%$ are identified within the "various tools" category. The 119 resources are shown in the following summary table (https:/ / bit.ly/3F8Dyw1 (accessed on 24 October 2021)):

The first item that stands out from the "hardware" category is robotics with $15.9 \%$. Among the 19 resources, were robots of very different types: KIBO [60,63-65] and Cubetto [66], which stand out for their wooden parts enabling better manipulation; BeeBot [42], which is a classic of educational robotics for its simplicity and potential; LEGO is present with its Mindstorms EV3 models [67]; and Education WeDo [68] or TurtleBot [69], related to the pioneering work of Seymour Papert [34].

The next item in the category is "board games" (13.44\%). Splash Code [70] or Coding Ocean [71] are games that work directional programming through in-game elements or a robot to clean the oceans. Finally, as "resource maker" we found Makey-Makey [72] or Arduino kits [73], with which countless inventions can be created.

In the "software" category, the first item is "visual programming" (19.32\%). In it, the most widely used ones were quickly found: Scratch [74] and Alice [75], given their run over the years. However, it can be observed that there is a large variety of more recent ones that made up a niche within the research: Code.org [76], Light-Bot [41] or Hopscotch [77], among 18 other resources. Another component of this category is pure and educational "programming languages" (10.92\%). Python [78] or Java [79] have a more professional profile, while RoboTIC [80] and VEE Primary Code [81] are designed more for education. Finally, with 7.56\%, we found nine digital tools of different types, such as MIT Media Lab: 
Moral Machine [82], to test our moral decisions or Mission Maker [83], with which we can make video game missions.

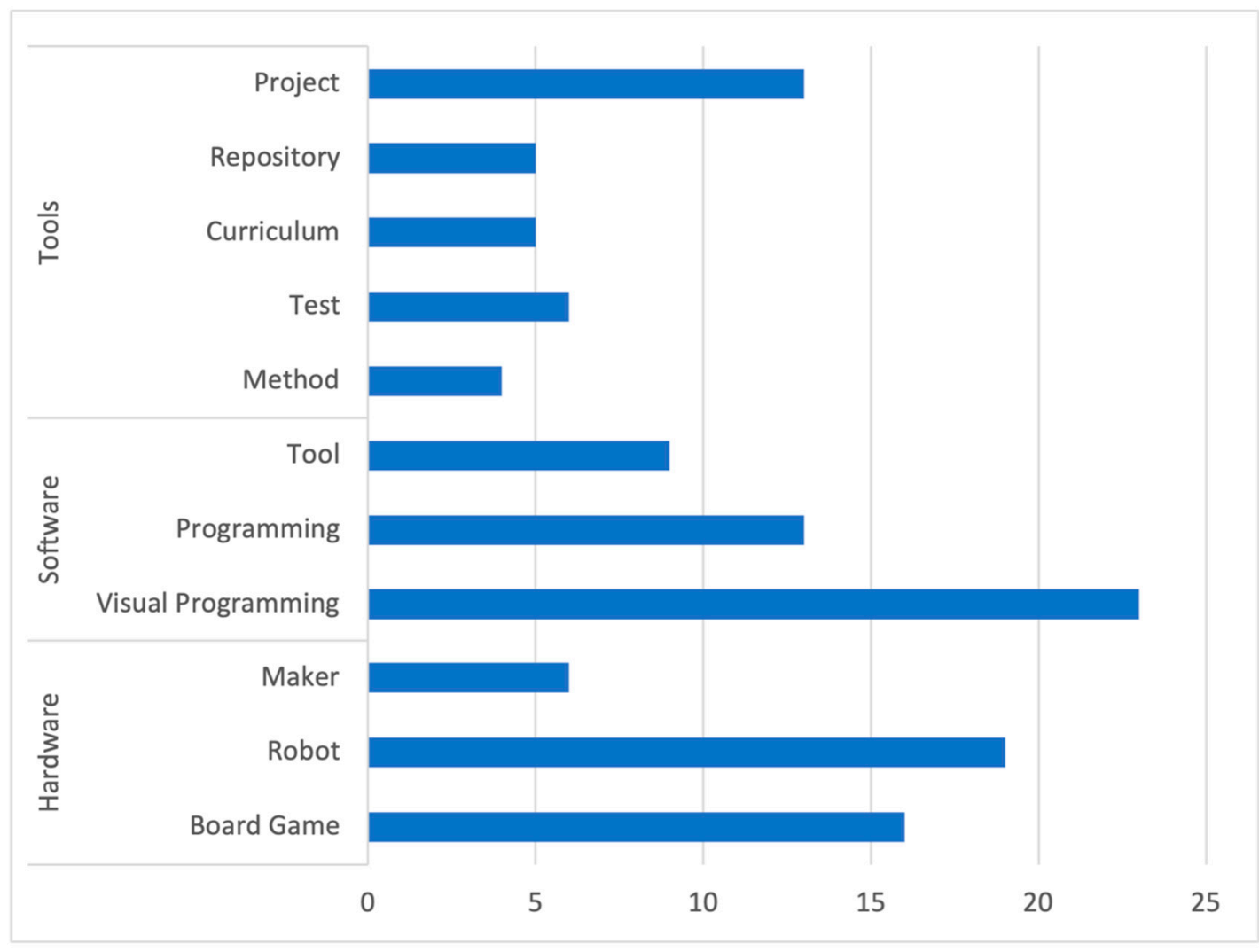

Figure 7. Number of types of resources used in publications.

The last category, entitled "Tools", includes a wide range of resources, among which "projects" (10.92\%), "tests" (5.04\%) and "repositories" (4.2\%) stand out. Among the former, one can find very diverse projects of varying impact. For example, the Bebras Computing Challenge [84], which is a worldwide project on CT development or Coding4Girls [85], a project whose interventions target the factors that lead girls not to choose computer science studies. Among the tools to evaluate the CT, different tests, such as the Computational thinking levels scale (CTLS) [86] or the Computational Thinking Test by Román-González et. al. [87], focus on the evaluation of the CT concept itself. Dr. Scratch allows us to test the projects created with the tool to find out which parts of the CT we are developing with them. Finally, among the five repositories, a multitude of resources were found, with CS Unplugged [88] standing out for its quantity and variety.

\section{Discussion and Conclusions}

At the end of the procedure followed for the SLR, it was possible to visualize the impact of CT in the practices analyzed through implementation strategies of some of the dimensions of the concept in the teaching-learning processes. With the analysis carried out, it was possible to answer the ten research questions initially established through a conceptual framework generated around the concept, the documentary elements of the texts that make up the review, the different thematic areas from where the research is conducted and the methodologies carried out in them. It was also made possible through a pedagogical framework born out of the form of inclusion of $\mathrm{CT}$, the different educational levels where it is included, the results of the research and the resources or tools directly related to CT. As such, the most important results of this systematic review can be explored from three perspectives. 
The conceptual network that originated in the analysis of the texts that make up the review explores the key concepts linked to $\mathrm{CT}$, as well as the existing relationships between them, in a way not seen before. Although authors, such as Fagerlund et al. [5], Cabrera [9], Kakavas and Ugolini [13] or Hsu et al. [15], had explored the concept of CT and even the dimensions proposed by Brennan and Resnick [26], through the representation of the current state of affairs, a more in-depth study was carried out. This new terminological framework allows for future research starting from less explored areas, such as the relationship between $\mathrm{CT}$ and digital competence.

Next, a documentary framework was presented and nourished, primarily, by the distribution of articles based on the dimensions that the authors worked on in their research. This same analysis was superimposed along with that of the quality of the journals in which their works were published. This double analysis is not found in previous reviews. However, it provides a detailed description of the most and least explored dimensions, which allows an analysis of future research niches.

Likewise, the co-authorship and co-citation maps made it possible to establish the existing relationships between authors. These relationships were produced both among themselves and with the referents in the field of CT. This analysis had not been carried out in this depth in previous reviews, so it offers an unprecedented field on which to base future research. Similarly, Marina Umaschi Bers of Tufts University and Yen Air Caballero-Gonzalez of the University of Salamanca were highlighted as the authors with the most publications in this review.

The next element that fed the documentary framework was the subject areas and disciplines of the journals in which the journal texts were published. Again, this type of analysis cannot be found in previous SLRs. The result of the analysis provides information for future projects, given that researchers will be able to opt for a broad scope of publication beyond educational and social sciences.

Hsu et al. [15] already analyzed the next documentary element: country, through a geographical analysis of the publications. Thus, it can be seen how the United States remains the primary power and Spain the second. However, the difference has been significantly reduced, from 55 to 10 . Although, in the present review, Greece is equal to the United Kingdom and China in terms of publications, which is very similar to the data provided by the previous review, it is Turkey that has undergone an increase that has earned it third place: a fact justified by the introduction of CT in Turkey's official curriculum in 2016.

The penultimate element that added value to the document analysis lies in the types of research. Although Kakavas and Ugolini [13] discussed the tools used for data extraction in their practices, the research approach and method were not analyzed. While this new data provides an overview of the research conducted in recent years, it will be future research that can be nourished by these results and, thus, seek less developed research as niches for possible research.

Finally, we proceeded to analyze the pedagogical framework, starting with the type of educational practices that were carried out. Hsu et al. [15] found that 74\% of the research was carried out in formal teaching contexts. However, at present, a balance has been generated between formal and non-formal contexts, with $48 \%$ in both. Likewise, for the first time, $4 \%$ of practices appeared to be carried out in both contexts in a combined manner.

These data led us to ask at what levels of formal education CT is introduced. Already in Kakavas and Ugolini [13], primary education was the main choice for researchers with $58.49 \%$ and, although it has decreased, it is still so today, with $40.02 \%$. However, higher education has grown from 7.54 to $20.01 \%$. Although it has grown from 7.54 to $9.66 \%$, early childhood education is still the option chosen by the fewest researchers to carry out their internships.

The next element that nurtured the pedagogical framework lies in the subjects in which the text practices are carried out. As can be seen, programming, computer science and mathematics dominated the sample; in fact, this is an exponential result to that obtained by 
Hsu et al. [15]. While programming used to lead with $25.40 \%$, it now leads with $63.48 \%$; a percentage that exceeds the sum of the three dominant ones with $55.72 \%$ : a collateral effect of accepting the statement that the $\mathrm{CT}$ is all about learning to program.

Hence, the importance of the type of resource used: connected or disconnected. Kakavas and Ugolini [13], in their review, already took this element into account. Their results showed that digital resources accounted for $64.15 \%$, compared to $40 \%$ today. This decrease is in favor of unplugged resources, which increased from 18.86 to $40 \%$. Combined or mixed resources are also on the rise, with an increase of $4.91 \%$. However, this is the first time that these data have been cross-referenced with educational level, where it is possible to better appreciate how resources are distributed depending on educational stage. These results add depth to those previously obtained and, of course, to the pedagogical framework.

Although the results provided the framework with indisputable potential, compared to the data of Kakavas and Ugolini [13], a clear similarity can be appreciated. So much so, that even the data from gender perspective hold the same sixth position. Therefore, its importance does not lie in frequency but in what the authors contribute to the whole. However, one of the elements that most enhanced the pedagogical framework was the existence of 119 resources collected from the texts. While Hsu et al. [15] collected the programming languages used in the practices they analyzed, the current review collected a complete classification of digital and analog resources, along with projects, repositories, tests and tools, providing support for the educational community working on CT.

The scope of this review was limited by the specific search terms used, the scientific databases used to perform the searches, the period in which the reviewed studies were published and the large final sample. However, the results emerging from this study provide useful insights for research at all levels of education. In this way, a general representation of the current state of computational thinking is provided.

In view of the results of the present SLR, it can be concluded that an adequate educational approach to CT implementation is needed. It requires a pure knowledge of the concept as a whole, its three dimensions and its didactics, in addition to the application of technological tools. The balance will generate a triad necessary to obtain profound results from the implementation of $\mathrm{CT}$. However, this interconnection requires a process of learning, reflection and organization.

Teacher training cannot, therefore, be an obstacle to its implementation. The need to increase the practices of both teachers in training and in-service teachers is appreciated. Although the data are encouraging, we must be aware that each well-trained teacher implies a classroom open to CT. This means a classroom that will benefit from its educational potential, which seeks not only an improvement in academic performance but also motivation, autonomy, the development of 21st-century skills, logical thinking, innovation and, of course, learning for the future.

Supplementary Materials: Checklist: https: / bit.ly /3G7S1tu (accessed on 29 December 2021). Selection: https:/ / bit.ly /3G3n35O (accessed on 24 October 2021). Resources: https:/ /bit.ly/3F8Dyw1 (accessed on 24 October 2021).

Author Contributions: Conceptualization, J.A.-B.; methodology, J.A.-B. and J.V.-B.; software, J.A.-B.; validation, J.A.-B. and J.V.-B.; formal analysis, J.A.-B. and J.V.-B.; investigation, J.A.-B., J.V.-B. and M.d.C.G.-A.; resources, M.d.C.G.-A.; data curation, J.V.-B.; writing-original draft preparation, M.d.C.G.-A.; writing-review and editing, M.d.C.G.-A.; visualization, J.V.-B.; supervision, J.V.-B. and M.d.C.G.-A.; project administration, J.A.-B.; funding acquisition, J.A.-B. and J.V.-B. All authors have read and agreed to the published version of the manuscript.

Funding: This publication has been made possible thanks to funding granted by the Consejería de Economía, Ciencia y Agenda Digital de la Junta de Extremadura and by the European Regional Development Fund of the European Union through the reference grant GR18071. And J.A.-B. is supported by a predoctoral contract granted by Ministry of Education, Culture and Sport of Spain (FPU15/05730).

Institutional Review Board Statement: Not applicable. 
Informed Consent Statement: Not applicable.

Data Availability Statement: Not applicable. The data for this study originated from secondary desk research.

Conflicts of Interest: The authors declare no conflict of interest.

\section{References}

1. Nouri, J.; Zhang, L.; Mannila, L.; Norén, E. Development of computational thinking, digital competence and 21st century skills when learning programming in K-9. Educ. Inq. 2020, 11, 1-17. [CrossRef]

2. Caeli, E.N.; Bundsgaard, J. Computational thinking in compulsory education: A survey study on initiatives and conceptions. Educ. Technol. Res. Dev. 2020, 68, 551-573. [CrossRef]

3. Rich, P.J.; Langton, M.B. Computational Thinking: Toward a Unifying Definition. In Competencies in Teaching, Learning and Educational Leadership in the Digital Age: Papers from CELDA 2014; Spector, J.M., Ifenthaler, D., Sampson, D.G., Isaias, P., Eds.; Springer International Publishing: Cham, Switzerland, 2016; pp. 229-242. [CrossRef]

4. Hoppe, H.U.; Werneburg, S. Computational Thinking-More Than a Variant of Scientific Inquiry! In Computational Thinking Education; Kong, S.-C., Abelson, H., Eds.; Springer: Singapore, 2019; pp. 13-30. [CrossRef]

5. Fagerlund, J.; Hakkinen, P.; Vesisenaho, M.; Viiri, J. Computational thinking in programming with scratch in primary schools: A systematic review. Comput. Appl. Eng. Educ. 2021, 29, 12-28. [CrossRef]

6. Palts, T.; Pedaste, M. A model for developing computational thinking skills. Inform. Educ. 2020, 19, 113-128. [CrossRef]

7. Xia, L.; Zhong, B. A systematic review on teaching and learning robotics content knowledge in K-12. Comput. Educ. 2018, 127, 267-282. [CrossRef]

8. Zhong, B.; Xia, L. A systematic review on exploring the potential of educational robotics in mathematics education. Int. J. Sci. Math. Educ. 2020, 18, 79-101. [CrossRef]

9. Cabrera, L. Teacher Preconceptions of Computational Thinking: A Systematic Literature Review. J. Technol. Teachol. Educ. 2019, 27, 305-333. Available online: https:/ / bit.ly/2WPocfv (accessed on 26 July 2021).

10. Taslibeyaz, E.; Kursun, E.; Karaman, S. How to Develop Computational Thinking: A Systematic Review of Empirical Studies. Inform. Educ. 2020, 19, 701-719. [CrossRef]

11. Popat, S.; Starkey, L. Learning to code or coding to learn? A systematic review. Comput. Educ. 2019, 128, 365-376. [CrossRef]

12. Zhang, L.; Nouri, J. A systematic review of learning computational thinking through Scratch in K-9. Comput. Educ. 2019, 141, 103607. [CrossRef]

13. Kakavas, P.; Ugolini, F.C. Computational thinking in primary education: A systematic literature review. Res. Educ. Media 2019, 11, 64-94. [CrossRef]

14. Tang, X.; Yin, Y.; Lin, Q.; Hadad, R.; Zhai, X. Assessing computational thinking: A systematic review of empirical studies. Comput. Educ. 2020, 148, 103798. [CrossRef]

15. Hsu, T.-C.; Chang, S.-C.; Hung, Y.-T. How to learn and how to teach computational thinking: Suggestions based on a review of the literature. Comput. Educ. 2018, 126, 296-310. [CrossRef]

16. Wing, J.M. Computational thinking. Commun. ACM 2006, 49, 33-35. [CrossRef]

17. Tikva, C.; Tambouris, E. Mapping computational thinking through programming in K-12 education: A conceptual model based on a systematic literature Review. Comput. Educ. 2021, 162, 104083. [CrossRef]

18. Gilchrist, P.O.; Alexander, A.B.; Green, A.J.; Sanders, F.E.; Hooker, A.Q.; Reif, D.M. Development of a pandemic awareness stem outreach curriculum: Utilizing a computational thinking taxonomy framework. Educ. Sci. 2021, 11, 109. [CrossRef] [PubMed]

19. Waterman, K.P.; Goldsmith, L.; Pasquale, M. Integrating computational thinking into elementary science curriculum: An examination of activities that support students' computational thinking in the service of disciplinary learning. J. Sci. Educ. Technol. 2020, 29, 53-64. [CrossRef]

20. Adler, R.F.; Kim, H. Enhancing future K-8 teachers' computational thinking skills through modeling and simulations. Educ. Inf. Technol. 2018, 23, 1501-1514. [CrossRef]

21. Ozturk, Z.; Dooley, C.M.; Welch, M. Finding the Hook: Computer Science Education in Elementary Contexts. J. Res. Technol. Educ. 2018, 50, 149-163. [CrossRef]

22. Alfayez, A.A.; Lambert, J. Exploring Saudi Computer Science Teachers' Conceptual Mastery Level of Computational Thinking Skills. Comput. Sch. 2019, 36, 143-166. [CrossRef]

23. Kale, U.; Akcaoglu, M.; Cullen, T.; Goh, D. Contextual factors influencing access to teaching computational thinking. Comput. Sch. 2018, 35, 69-87. [CrossRef]

24. Munn, Z.; Peters, M.D.J.; Stern, C.; Tufanaru, C.; McArthur, A.; Aromataris, E. Systematic review or scoping review? Guidance for authors when choosing between a systematic or scoping review approach. BMC Med. Res. Methodol. 2018, 18, 143. [CrossRef]

25. Tricco, A.C.; Lillie, E.; Zarin, W.; O’Brien, K.K.; Colquhoun, H.; Levac, D.; Moher, D.; Peters, M.D.J.; Horsley, T.; Weeks, L.; et al. PRISMA Extension for Scoping Reviews (PRISMA-ScR): Checklist and Explanation. Ann. Intern. Med. 2018, 169, 467-473. [CrossRef]

26. Brennan, K.; Resnick, M. New frameworks for studying and assessing the development of computational thinking. In Proceedings of the 2012 Annual Meeting of the American Educational Research Association, Vancouver, BC, Canada, 13-17 April 2012. 
27. Chuang, H.-C.; Hu, C.-F.; Wu, C.C.; Lin, Y.-T. Computational thinking curriculum for K-12 education-A delphi survey. In Proceedings of the 2015 International Conference on Learning and Teaching in Computing and Engineering, Taipei, Taiwan, 9-12 April 2015; pp. 213-214. [CrossRef]

28. Moreno-León, J.; Robles, G.; Román-González, M. Towards Data-Driven Learning Paths to Develop Computational Thinking with Scratch. IEEE Trans. Emerg. Top. Comput. 2020, 8, 193-205. [CrossRef]

29. Fierro, S.L.; Montenegro, G.; López, C. Towards a Conceptual Framework to Measure the Impact of Computational Thinking on College Students' Mathematics Learning. RISTI—Rev. Iber. Sist. E Tecnol. Inf. 2019, 2019, 619-631. Available online: https://bit.ly/3G10E9p (accessed on 11 October 2021).

30. Barr, V.; Stephenson, C. Bringing computational thinking to K-12: What is Involved and what is the role of the computer science education community? ACM Inroads 2011, 2, 48-54. [CrossRef]

31. Bers, M.U.; Flannery, L.; Kazakoff, E.R.; Sullivan, A. Computational thinking and tinkering: Exploration of an early childhood robotics curriculum. Comput. Educ. 2014, 72, 145-157. [CrossRef]

32. Grover, S.; Pea, R. Computational Thinking in K-12 A Review of the State of the Field. Educ. Res. 2013, 42, 38-43. [CrossRef]

33. Lye, S.Y.; Koh, J.H.L. Review on teaching and learning of computational thinking through programming: What is next for K-12? Comput. Hum. Behav. 2014, 41, 51-61. [CrossRef]

34. Papert, S. Mindstorms: Children, Computers, and Powerful Ideas; Basic Books: New York, NY, USA, 1980.

35. Resnick, M.; Maloney, J.; Monroy-Hernández, A.; Rusk, N.; Eastmond, E.; Brennan, K.; Millner, A.; Rosenbaum, E.; Silver, J.; Silverman, B.; et al. Scratch: Programming for all. Commun. ACM 2009, 52, 60-67. [CrossRef]

36. Weintrop, D.; Beheshti, E.; Horn, M.S.; Orton, K.; Jona, K.; Trouille, L.; Wilensky, U. Defining Computational Thinking for Mathematics and Science Classrooms. J. Sci. Educ. Technol. 2016, 25, 127-147. [CrossRef]

37. Wing, J.M.; 秀之翻訳, 中島. Computational Thinking 計算論的思考. 情報処理 2015, 56, 584-587. Available online: https://bit.ly/ 3BpofhO (accessed on 6 October 2021).

38. Bocconi, S.; Chioccariello, A.; Dettori, G.; Ferrari, A.; Engelhardt, K. Developing Computational Thinking in Compulsory Education. Implications for policy and practice. EUR—Sci. Technol. Res. Rep. 2016. [CrossRef]

39. Mouza, C.; Pan, Y.-C.; Yang, H.; Pollock, L. A multiyear investigation of student computational thinking concepts, practices, and perspectives in an after-school computing program. J. Educ. Comput. Res. 2020, 58, 1029-1056. [CrossRef]

40. Csapo, G. Placing Event-Action-based Visual Programming in the Process of Computer Science Education. Acta Polytech. Hung. $\mathbf{2 0 1 9}, 16,35-57$

41. Monjelat, N.; Lantz-Andersson, A. Teachers' narrative of learning to program in a professional development effort and the relation to the rhetoric of computational thinking. Educ. Inf. Technol. 2020, 25, 2175-2200. [CrossRef]

42. Caballero-Gonzalez, Y.A.; García-Valcarcel Muñoz-Repiso, A. Enhancing computational thinking skills in early childhood education: Learning experience through tangible and graphical interfaces. Rev. Latinoam. Technol. Educ.-Relatec. 2019, 18, 133-149. [CrossRef]

43. Christidou, D.; Papavlasopoulou, S.; Giannakos, M. Using the lens of science capital to capture and explore children's attitudes toward science in an informal making-based space. Inf. Learn. Sci. 2021, 12, 317-340. [CrossRef]

44. Egbert, J.; Shahrokni, S.A.; Abobaker, R.; Borysenko, N. "It's a chance to make mistakes": Processes and outcomes of coding in 2nd grade classrooms. Comput. Educ. 2021, 168, 104173. [CrossRef]

45. Rijke, W.J.; Bollen, L.; Eysink, T.H.S.; Tolboom, J.L.J. Computational thinking in primary school: An examination of abstraction and decomposition in different age groups. Inform. Educ. 2018, 17, 77-92. [CrossRef]

46. Rojas-Lopez, A.; García-Peñalvo, F.J. Assessment of computational thinking skills to predict student learning and retention in the subject programming computer in higher education. Red-Rev. Educ. Distancia 2020, 20, 4. [CrossRef]

47. Tsakeni, M. Preservice teachers' use of computational thinking to facilitate inquiry-based practical work in multiple-deprived classrooms. Eurasia J. Math. Sci. Technol. Educ. 2021, 17, em1933. [CrossRef]

48. Busuttil, L.; Formosa, M. Teaching computing without computers: Unplugged computing as a pedagogical strategy. Inform. Educ. 2020, 19, 569-587. [CrossRef]

49. Price, C.B.; Price-Mohr, R.M. An evaluation of primary school children coding using a text-based language (java). Comput. Sch. 2018, 35, 284-301. [CrossRef]

50. Chen, G.; He, Y.; Yang, T. An ISMP approach for promoting design innovation capability and its interaction with personal characters. IEEE Access 2020, 8, 161304-161316. [CrossRef]

51. Calandra, B.; Renken, M.; Cohen, J.D.; Hicks, T.; Ketenci, T. An examination of a group of middle school students' engagement during a series of afterschool computing activities in an urban school district. Techtrends 2021, 65, 17-25. [CrossRef]

52. Díaz-Lauzurica, B.; Moreno-Salinas, D. Computational thinking and robotics: A teaching experience in compulsory secondary education with students with high degree of apathy and demotivation. Sustainability 2019, 11, 5109. [CrossRef]

53. Arfe, B.; Vardanega, T.; Ronconi, L. The effects of coding on children's planning and inhibition skills. Comput. Educ. 2020, 148, 103807. [CrossRef]

54. Yu, X.; Guo, X. Case study on "STEM+Computational Thinking" Education Model in Chinese K-12 Schools. J. Sci. Educ. 2018, 19, 163-177. Available online: https:/ / bit.ly/3EpBno9 (accessed on 11 October 2021).

55. Relkin, E.; de Ruiter, L.E.; Bers, M.U. Learning to code and the acquisition of computational thinking by young children. Comput. Educ. 2021, 169, 104222. [CrossRef] 
56. Ríos Félix, J.M.; Zatarain Cabada, R.; Barrón Estrada, M.L. Teaching computational thinking in Mexico: A case study in a public elementary school. Educ. Inf. Technol. 2020, 25, 5087-5101. [CrossRef]

57. Garcia-Valcarcel Munoz-Repiso, A.; Caballero-Gonzalez, Y.-A. Robotics to develop computational thinking in early Childhood Education. Comunicar 2019, 27, 63-72. [CrossRef]

58. del Olmo-Munoz, J.; Cozar-Gutierrez, R.; Antonio Gonzalez-Calero, J. Computational thinking through unplugged activities in early years of Primary Education. Comput. Educ. 2020, 150, 103832. [CrossRef]

59. Chiazzese, G.; Fulantelli, G.; Pipitone, V.; Taibi, D. Involucrando a los niños de educación primaria en el Pensamiento Computacional: Diseñando y desarrollando videojuegos. Educ. Knowl. Soc. EKS 2018, 19, 63-81. [CrossRef]

60. Jurado, E.; Fonseca, D.; Coderch, J.; Canaleta, X. Social steam learning at an early age with robotic platforms: A case study in four schools in Spain. Sensors 2020, 20, 3698. [CrossRef] [PubMed]

61. Miller, J. STEM education in the primary years to support mathematical thinking: Using coding to identify mathematical structures and patterns. Zdm-Math. Educ. 2019, 51, 915-927. [CrossRef]

62. Esteve-Mon, F.M.; Adell-Segura, J.; Nebot, M.A.L.; Novella, G.V.; Aparicio, J.P. The development of computational thinking in student teachers through an intervention with educational robotics. J. Inf. Technol. Educ. Innov. Pract. 2019, 18, 139-152. [CrossRef]

63. Bers, M.U. Coding as another language: A pedagogical approach for teaching computer science in early childhood. J. Comput. Educ. 2019, 6, 499-528. [CrossRef]

64. González-González, C.S.; Holz, V.V.; Moro, A.I.; García, L.C.; Franco, M.D.G. Educational robotics in inclusive contexts: The case of the hospital classrooms. Educ. XX1 2021, 24, 375-403. [CrossRef]

65. Hassenfeld, Z.R.; Govind, M.; de Ruiter, L.E.; Bers, M.U. If you can program you can write: Learning introductory programming across literacy levels. J. Inf. Technol. Educ.-Res. 2020, 19, 65-85. [CrossRef]

66. Miranda Pinto, M.S.; Osorio, A. Learn to program in preschool: Analysis with the participation scale. Pixel-Bit-Rev. Medios Educ. 2019, 55, 133-156. [CrossRef]

67. Taylor, K.; Baek, Y. Grouping matters in computational robotic activities. Comput. Hum. Behav. 2019, 93, 99-105. [CrossRef]

68. Chiazzese, G.; Arrigo, M.; Chifari, A.; Lonati, V.; Tosto, C. Educational Robotics in Primary School: Measuring the Development of Computational Thinking Skills with the Bebras Tasks. Informatics 2019, 6, 43. [CrossRef]

69. Nam, K.W.; Kim, H.J.; Lee, S. Connecting Plans to Action: The Effects of a Card-Coded Robotics Curriculum and Activities on Korean Kindergartners. Asia-Pac. Educ. Res. 2019, 28, 387-397. [CrossRef]

70. von Wangenheim, C.G.; Medeiros, G.A.E.S.D.; Filho, R.M.; Petri, G.; Pinheiro, F.D.C.; Ferreira, M.N.F.; Hauck, J.C.R. Splash code-A board game for learning an understanding of algorithms in middle school. Inform. Educ. 2019, 18, 259-280. [CrossRef]

71. Chen, K.-Z.; Chi, H.-H. Novice young board-game players' experience about computational thinking. Interact. Learn. Environ 2020, 1-13. [CrossRef]

72. Yin, Y.; Hadad, R.; Tang, X.; Lin, Q. Improving and assessing computational thinking in maker activities: The integration with physics and engineering learning. J. Sci. Educ. Technol. 2020, 29, 189-214. [CrossRef]

73. Psycharis, S.; Kotzampasaki, E. The impact of a stem inquiry game learning scenario on computational thinking and computer self-confidence. Eurasia J. Math. Sci. Technol. Educ. 2019, 15, 103071. [CrossRef]

74. Maraza-Quispe, B.; Maurice, A.; Melina, O.; Marianela, L.; Henry, L.; Cornelio, W.; Ernesto, L. Towards the Development of Computational Thinking and Mathematical Logic through Scratch. Int. J. Adv. Comput. Sci. Appl. 2021, 12, 332-338. [CrossRef]

75. Dag, F. Prepare pre-service teachers to teach computer programming skills at K-12 level: Experiences in a course. J. Comput. Educ. 2019, 6, 277-313. [CrossRef]

76. Ciftci, S.; Bildiren, A. The effect of coding courses on the cognitive abilities and problem-solving skills of preschool children. Comput. Sci. Educ. 2020, 30, 3-21. [CrossRef]

77. Zha, S.; Jin, Y.; Moore, P.; Gaston, J. Hopscotch into Coding: Introducing Pre-Service Teachers Computational Thinking. TechTrends 2019, 64, 17-28. [CrossRef]

78. Morton, C.E.; Smith, S.F.; Lwin, T.; George, M.; Williams, M. Computer programming: Should medical students be learning it? J. Med. Internet Res. 2019, 5, e11940. [CrossRef] [PubMed]

79. Choi, S.-Y. Development of an Instructional Model Based on Constructivism for Fostering Computational Thinking. Int. J. Innov. Technol. Explor. Eng. 2019, 8, 381-385. Available online: https://bit.ly/32PQie5 (accessed on 11 October 2021).

80. Schez-Sobrino, S.; Vallejo, D.; Glez-Morcillo, C.; Redondo, M.A.; Castro-Schez, J.J. RoboTIC: A serious game based on augmented reality for learning programming. Multimed. Tools Appl. 2020, 79, 34079-34099. [CrossRef]

81. Hijon-Neira, R.; Perez-Marin, D.; Pizarro, C.; Connolly, C. The effects of a visual execution environment and makey makey on primary school children learning introductory programming concepts. IEEE Access 2020, 8, 217800-217815. [CrossRef]

82. Seoane Pardo, A.M. Computational Thinking between Philosophy and STEM-Programming Decision Making Applied to the Behavior of "Moral Machines" in Ethical Values Classroom. Rev. Iberoam. Technol. Aprendiz. 2018, 13, 20-29. [CrossRef]

83. de Paula, B.H.; Burn, A.; Noss, R.; Valente, J.A. Playing Beowulf: Bridging computational thinking, arts and literature through game-making. Int. J. Child-Comput. Interact. 2018, 16, 39-46. [CrossRef]

84. Hsiao, H.-S.; Lin, Y.-W.; Lin, K.-Y.; Lin, C.-Y.; Chen, J.-H.; Chen, J.-C. Using robot-based practices to develop an activity that incorporated the 6E model to improve elementary school students' learning performances. Interact. Learn. Environ. 2019. [CrossRef] 
85. Alden, D.; Tramonti, M. Computational design thinking and physical computing: Preliminary observations of a pilot study. Robotics 2020, 9, 71. [CrossRef]

86. Durak, H.Y.; Yilmaz, F.G.K.; Bartin, R.Y. Computational thinking, programming self-efficacy, problem solving and experiences in the programming process conducted with robotic activities. Contemp. Educ. Technol. 2019, 10, 173-197. [CrossRef]

87. Román-Gonzalez, M.; Pérez-González, J.C.; Jiménez-Fernández, C. Test de Pensamiento Computacional: Diseño y psicometría general [Computational Thinking Test: Design \& general psychometry]. In Proceedings of the III Congreso Internacional Sobre Aprendizaje, Innovación y Competitividad, Madrid, Spain, 14-16 October 2015. [CrossRef]

88. El-Hamamsy, L.; Chessel-Lazzarotto, F.; Bruno, B.; Roy, D.; Cahlikova, T.; Chevalier, M.; Parriaux, G.; Pellet, J.-P.; Lanarès, J.; Zufferey, J.D.; et al. A computer science and robotics integration model for primary school: Evaluation of a large-scale in-service K-4 teacher-training program. Educ. Inf. Technol. 2021, 26, 2445-2475. [CrossRef] 